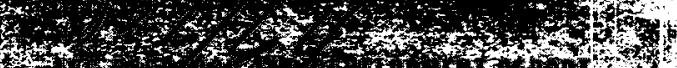

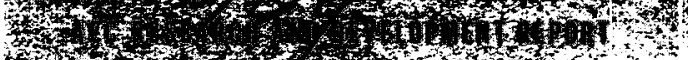

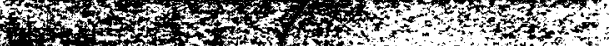

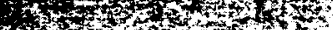

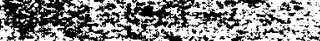

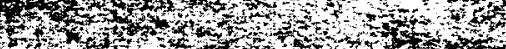

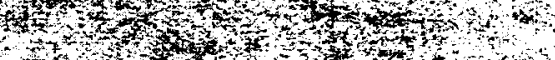

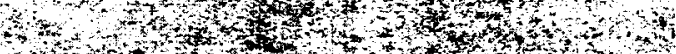

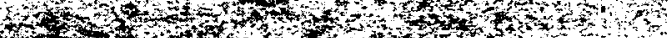

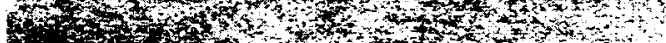

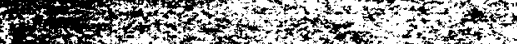

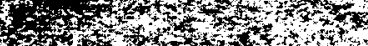

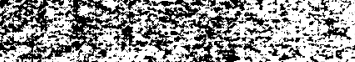

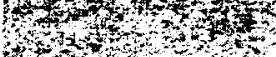

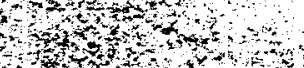

$+\infty+2+\infty$

(7)

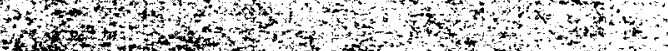

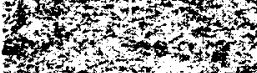

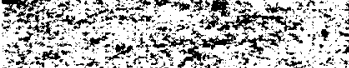

$2 .+2,+,+,+3$

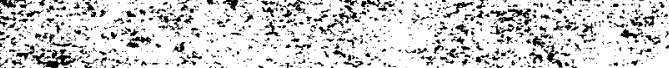

6 .

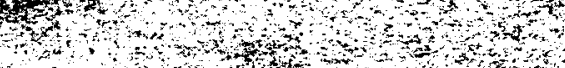

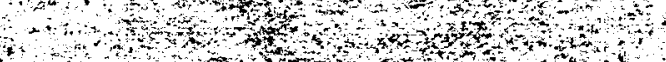

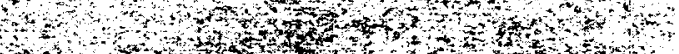

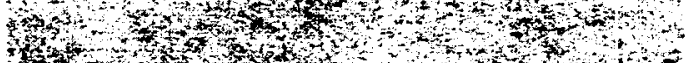

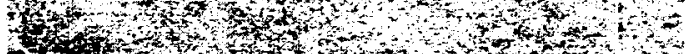

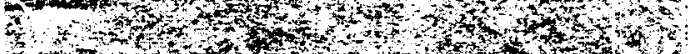

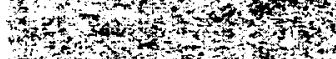

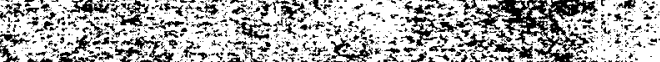

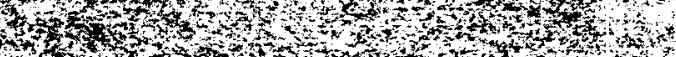

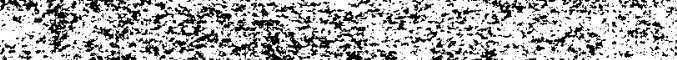

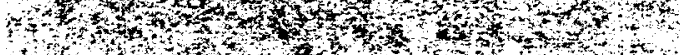

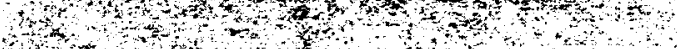

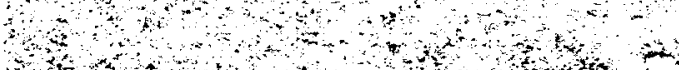

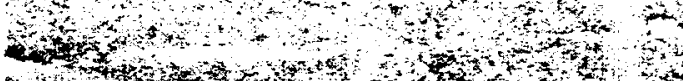

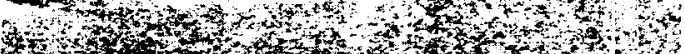

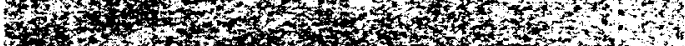

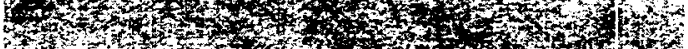

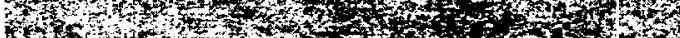

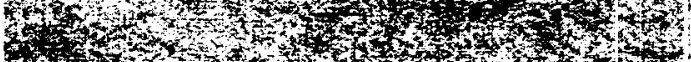

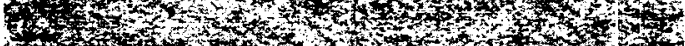
3.



AUTHOR:

G. B. Seaborn

MASTR

\title{
A FIXED FILTER PAPER ALPHA AIR MQNITOR
}

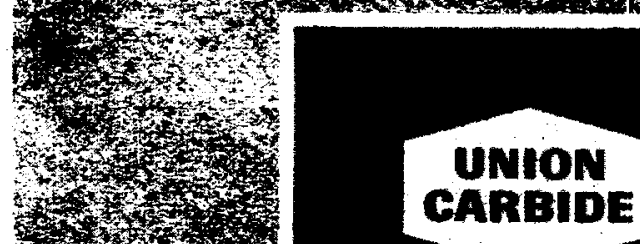

\section{UNION CARBIDE CORPORATION}

NUCLEAR DIVISION

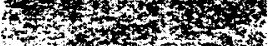

$4+3 x+3$

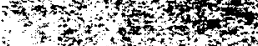

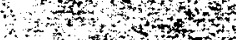

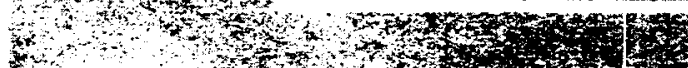

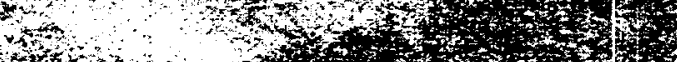

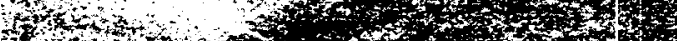

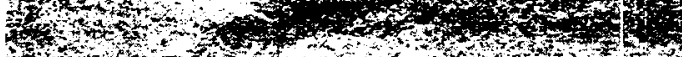

W

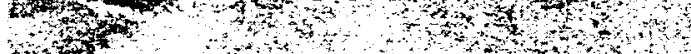

\section{Operating the}

OAK RIDGE GASEOUS DIFFUSION PLANT - OAK RIDGE NATIONAL LABORATORY

OAK RIDGE Y.12 PLANT

- PADUCAH gaseous DIFFusION PLANT

For the Atomic Energy Commission 
$x^{2} x^{x}$

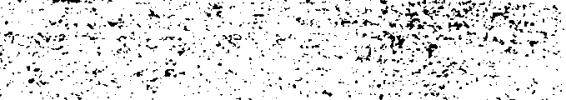

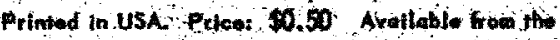

Ofte of Toelinfed Servigioy:

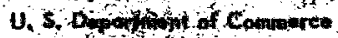

Wastrington 20, DiC.

\section{LEGAL MatieE}

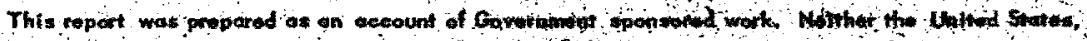

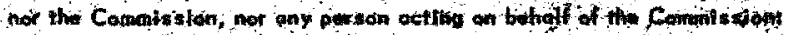

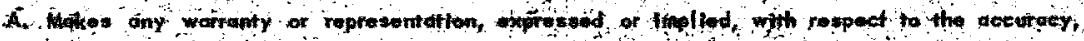

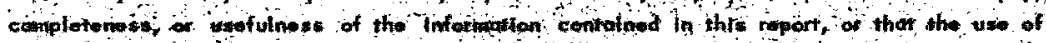

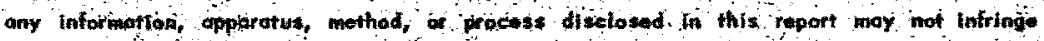
privately owned right as as

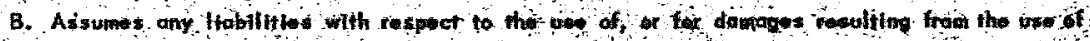

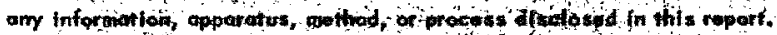

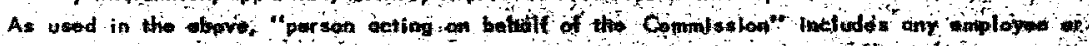

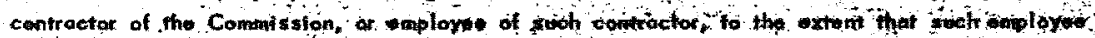

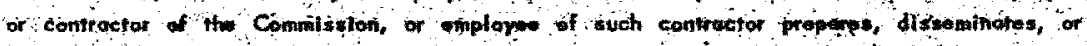

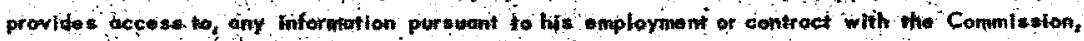
or his enployent with such compector. 
$\begin{aligned} & \text { Date of Issue: March 23, } 1964 \quad \text { Report Number: K-1589 } \\ & \text { Subject Category: INSTRUMENTS } \\ & \text { (TID 4500, 26th Ed.) }\end{aligned}$

A FIXED FILTER PAPER ALPHA AIR MONITOR

G. B. Seaborn

Instrument Development Department

Technical Division

UNION CARBIDE CORPORATION

NUCLEAR DIVISION

Oak Ridge Gaseous Diffusion Plant

Oak Ridge, Tennessee 


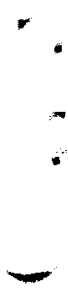

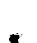

$-$ 


\section{DISCLAIMER}

This report was prepared as an account of work sponsored by an agency of the United States Government. Neither the United States Government nor any agency thereof, nor any of their employees, makes any wartanty, express or implied, or assumes any legal liability or responsibility for the accuracy, completeness, or usefulness of any information, apparatus, product, or process disclosed, or represents that its use would not infringe privately owned rights. Reference herein to any specific commercial product, process, or service by trade name, trademark, manufacturer, or otherwise does not necessarily constitute or imply its endorsement, recommendation, or favoring by the United States Government or any agency thereof. The views and opinions of authors expressed herein do not necessarily state or reflect those of the United States Government or any agency thereof. 


\section{DISCLAIMER}

Portions of this document may be illegible in electronic image products. Images are produced from the best available original document. 
Report Number: K-1589

\author{
Subject Category: INSTRUMENTS \\ Title: A FIXED FILTER PAPER AIPHA AIR \\ MONITOR \\ Author: G. B. Seaborn
}

\begin{abstract}
A B S T R A C T
An instrument has been developed for the detection of uranium dust in the atmosphere. The principle feature of this device is its ability to indicate a gross release of alpha radiation within a few minutes of its occurrence. The unit will sound an alarm when either the indicated level or the rate of increase exceeds preset values above normal background variations.
\end{abstract}


.

$-$

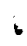

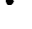

. 


\section{INTRODUCTION}

Measuring the amount of Iong-Iived alpha contamination resulting from airborne uranium dust is a health physics problem. One method of measuring the amount of long-lived alpha contamination in environmental air consists of drawing a measured volume of the air through a filter and measuring the alpha radioactivity remaining on the filter after allowing an appropriate time for natural atmospheric radioactivity to decay. This method requires a time lapse of approximately five hours between collection and analysis.

The following circumstances make it difficult to monitor an area for airborne uranium dust and to indicate that a significant alpha radiation level exists:

1. The permissible amount of airborne uranium dust in a working area is very small. At the Oak Ridge Gaseous Diffusion Plant the P.A.I. (plant allowable limit) is 200 disintegrations per minute per cubic meter.

2. The size of the dust particles formed during a uranium hexafluoride release varies with atmospheric conditions, but much of it approaches the size of atmospheric dust.

3. It is impossible, using the method described in this report, to collect the uranium dust that results from a uranium hexafluoride release from a known quantity of air without collecting the radon and thoron daughter products which cling to atmospheric dust.

4. The interfering alpha radiation from short-lived radon and thoron daughter products is often ten times greater than the alpha radiation from the permissible amount of airborne uranium dust.

5. Natural background from radon and thoron varies greatly as meteorological conditions change.

This report describes the design of an instrument which filters environmental air at a known, constant rate, monitors the filtrate for alpha activity, and indicates when this activity increases at a rate greater than would be expected from normal background variations. The instrument is able to indicate a gross release of alpha radiation within a few minutes of its occurrence. 


\section{APPARATUS}

A unique feature of the fixed filter paper alpha air monitor is the manner in which radioactivity is monitored. Environmental air is continuously drawn through a piece of filter paper. Beginning with a clean filter, dust from the atmosphere with its associated alpha activity slowly builds up on the surface of the paper. This buildup continues until a quasiequilibrium condition occurs in which the rate of arrival of new alpha particles is equal to the rate of decay of the material previously collected. This equilibrium level varies slowly as the natural background activity level varies. A scintillation detector continuously monitors the alpha activity on the paper. Panel meters indicate both the level of activity and the rate of increase of this level. The instrument is provided with a visible and audible alarm which will activate if either the level or the rate of increase of the level exceeds adjustable preset values.

Figure 1 is a simplified diagram of the basic components of the instrument. The vacuum pump draws air through the filter paper at a nominal flow of $6 \mathrm{scfm}$. The filter consists of a disc of Millipore type AA paper, 121 millimeters in diameter, backed up by a disc of Whatman No. 41 paper. The backup filter is necessary because of the fragility of the Millipore paper. The Millipore filter is a thin, porous membrane material of pure cellulose acetate containing millions of pores of about 0.8 micron diameter. These pores permit a high air flow without excessive plugging. Another desirable characteristic of this paper is its surface retention of particles. The collected dust is evenly distributed on the surface and not embedded in the paper; thus, the radiation absorption by the paper and the dust itself is minimal. The filter paper may be removed from the instrument at any time and checked for alpha activity by ashing and residue counting by the standard method. The gauge reading is a measure of the pressure drop across the filter and serves to indicate a need to renew the paper because of excessive plugging. The filter is considered to be usable until the flow drops twenty per cent, usually a period of seven to ten days. The vacuum pump is an integral unit driven by a one-half horsepower motor, and has a rating of $10.5 \mathrm{cfm}$. of free air. The pump is equipped with an oil filter in the discharge stream which drains back into the suction oil reservoir, thus providing a closed recirculating oiling system. An oil mist trap has been added to the pump to catch any droplets which may be discharged with the exhaust stream.

Figure 2 is a schematic diagram of the electronic portion of the instrument. The alpha detector is an Oak Ridge National Laboratory's Model Q-2IOI unit modified by substitution of a thinner window assembly to increase the sensitivity. The active element is a zinc sulphide coated block of acrylic plastic 4.5 inches square. The phototube TI is light coupled to the block. The output of the phototube is amplified through four stages (T2-T5) with an over-all gain of fifty. The resultant pulses trigger a one shot multivibrator (T6, T7). Its square wave output is integrated across 019 and amplified by three stages 
(T8-T10). The collector current of TlO is proportional to the count rate and is displayed on both a meter (MI) and strip chart recorder. This current also develops a voltage across $\mathrm{R} 57$ which acts as an input signal to a differentiating amplifier (C2O, TII, TI2). The collector current of TI2 as indicated on M2 is proportional to the rate of increase of the input voltage and is a measure of the rate of increase of the count rate. The fraction of the voltage across $R 57$ is adjustable and allows the sensitivity of the differentiating circuit to be varied.

Both meters are equipped with adjustable high alarm contacts; therefore, either a high count rate caused by an accumulation of radioactivity, or a high alarm rate caused by a sudden increase in count rate, will actuate the alarm. Switch 55 is a range switch which allows the range of the instrument in terms of count rate to be doubled from the normal $0-20,000$ counts per minute to $0-40,000$ counts per minute. When operating on the high range, the alarm sensitivity is halved.

Figures 3, 4, and 5 are photographs of the front, rear, and top of the instrument. The cabinet measures 13 inches high, 15 inches deep, and 21-1/2 inches wide. Total weight is 100 pounds. The all solid state electronic circuits are constructed on plug-in printed circuit boards. All of the components are standard except for capacitor C2O. This capacitor is of special manufacture to give an exceptionally low leakage current. The nominal leakage current is one-tenth microampere at five volts.

\section{CALIBRATION AND PERFORMANCE}

The count rate portion of the instrument is calibrated using standard 2-1/2 inch diameter disc alpha sources in place of the filter paper. Figure 6 is a graph of a typical calibration performed in this manner.

The alarm rate circuit cannot be calibrated directly because of the difficulty in generating a source of increasing activity. Instead, it is calibrated using a combination calculation-substitution method as follows: Upon receipt of the differentiating capacitor C2O from the manufactuer, it is checked for capacity and leakage current. It is then connected in a simple differentiating circuit in which the applied voltage is a positive ramp function obtained from a motor driven potentiometer. The rate of change of the ramp voltage is approximately that which will cause the alarm rate meter to read full scale. The differentiating current of this circuit is monitored and the value corrected by calculation as required to the exact value which will be furnished by potentiometer $\mathrm{R} 57$ in the count rate circuit. The alarm rate circuit is then adjusted with this value of current as an input from an external current source.

Figure 7 is a graph showing the time required for the instrument to alarm under the following conditions: 
1. The background alpha radiation is zero.

2. The initial alpha radiation is zero; i.e., the detected activity is zero at the onset of the event causing the alarm.

3. The alpha radiation is collected at a constant rate with a flow of 5.9 sefm.

4. The count rate and alarm rate set points are both at 100 per cent.

5. The alarm sensitivity is set at 10 ( 100 per cent).

6. The full scale count rate is $20,000 \mathrm{cpm}$.

The portion of the curve betweer 1 and 10 P.A.I. indicates an alarm would occur from an increase in the rate of activity. The portion of the curve between $O$ and I P.A.I. indicates an alarm would occur from an accumulation of activity. Obviously, if the background were increasing, or if the background were above zero, the instrument would be more sensitive to alarm, and less sensitive if the background were decreasing.

Figure 8 is a chart recording of the background alpha radiation for two consecutive days. Note that the characteristic of the recording is similar for the two days. This is typical in that the background rises after sunset as the air cools, and falls after sunrise as the air warms.

Typical responses to step increases in input are shown by the chart recordings of figure 9 . These charts were also obtained at a maximum alarm sensitivity.

This project was completed in October 1963.

\section{ACKNNOWLEDGEMENTT}

The author wishes to acknowledge the contributions of Messrs. R. C. Ritter, R. W. Schede, anā W. O. Gentry, who have furnished technical support for this project. 


\section{BIBLIOGRAPHY}

1. Lapp, R. E., and Andrews, H. I., Nuclear Radiation Physics. Prentice-Hall, Inc. (1948), pps. 110, 115.

2. D.A.T.A. Transistor Characteristics Tabulation. Derivations and Tabulation Associates. (1963).

3. Mathematical Tables. Chemical Rubber Publishing Company. (1947).

4. Transistor Manual (6th Edition), General Electric Company. (1962).

5. Gentry, W. O., Schede, R. W., and Smith, R. C., Monitors for Alpha Air Contamination. (AECL-802) Paper 2.17 (1959).

6. Gentry, W. O., and Seaborn, G. B., Detailed Design of a Fixed Filter Paper Alpha Air Monitor with Less than Fifteen Minutes Response Time. (USAEC) Report TID-1.2435 (1961).

7. Gentry, W. O., and Seaborn, G. B., A Fast Response Monitor for Air-Borne Uranium Dust. (USAEC) Report TID-13175 (1961).

8. Gentry, W. O., Atmospheric Radioactivity and Its Relation to Monitors for Air-Borne Uranium Dust. (USAEC) TID-16803 (1962).

9. Engineering Notebook No. 3908 (assigned to R. C. Ritter), UCNC.

10. Engineering Notebooks INos. 3940, 4I51, 4308, and 4670 (assigned to G. B. Seaborn) UCNC. 


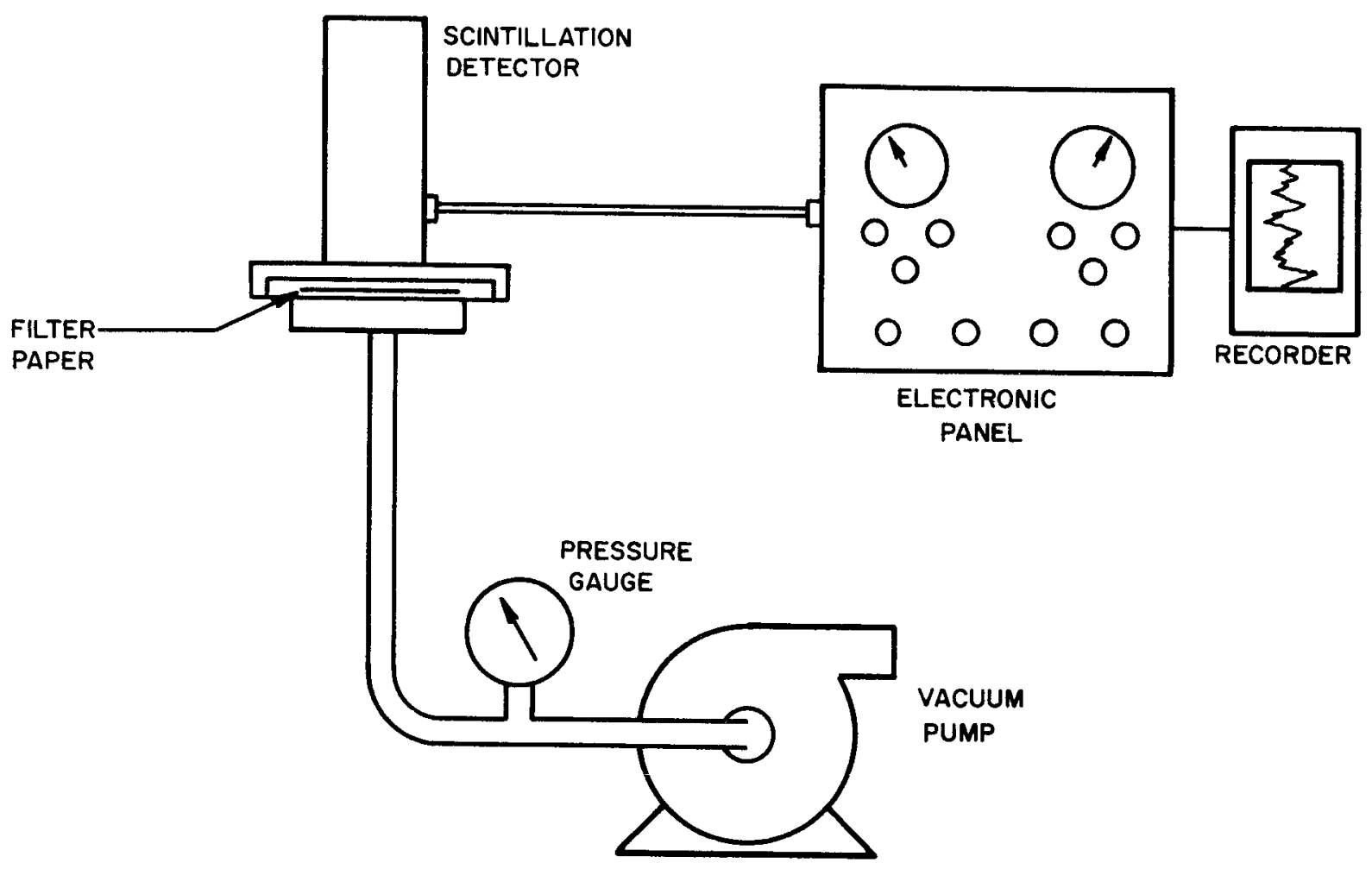

Figure 1

BASIC AIR MONITOR INSTRUMENT 


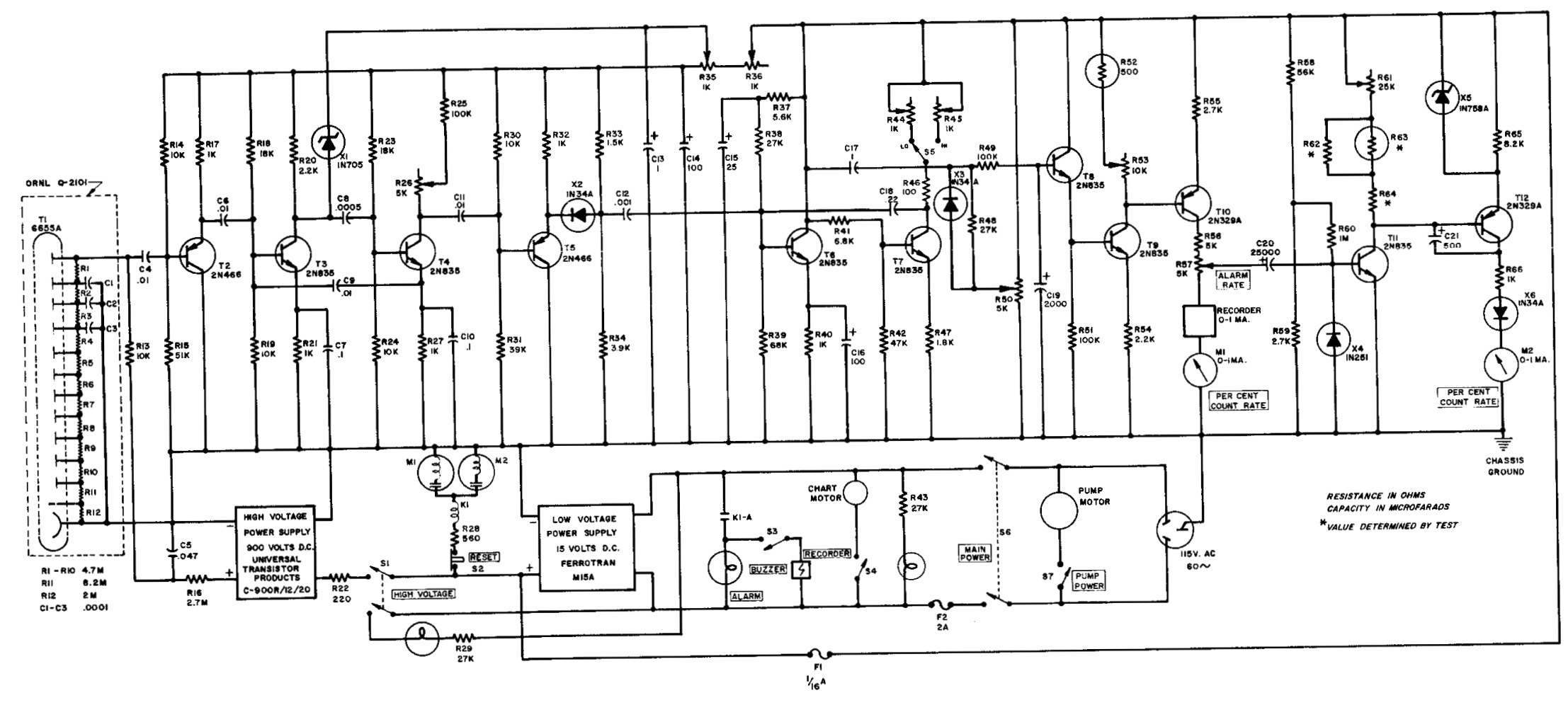




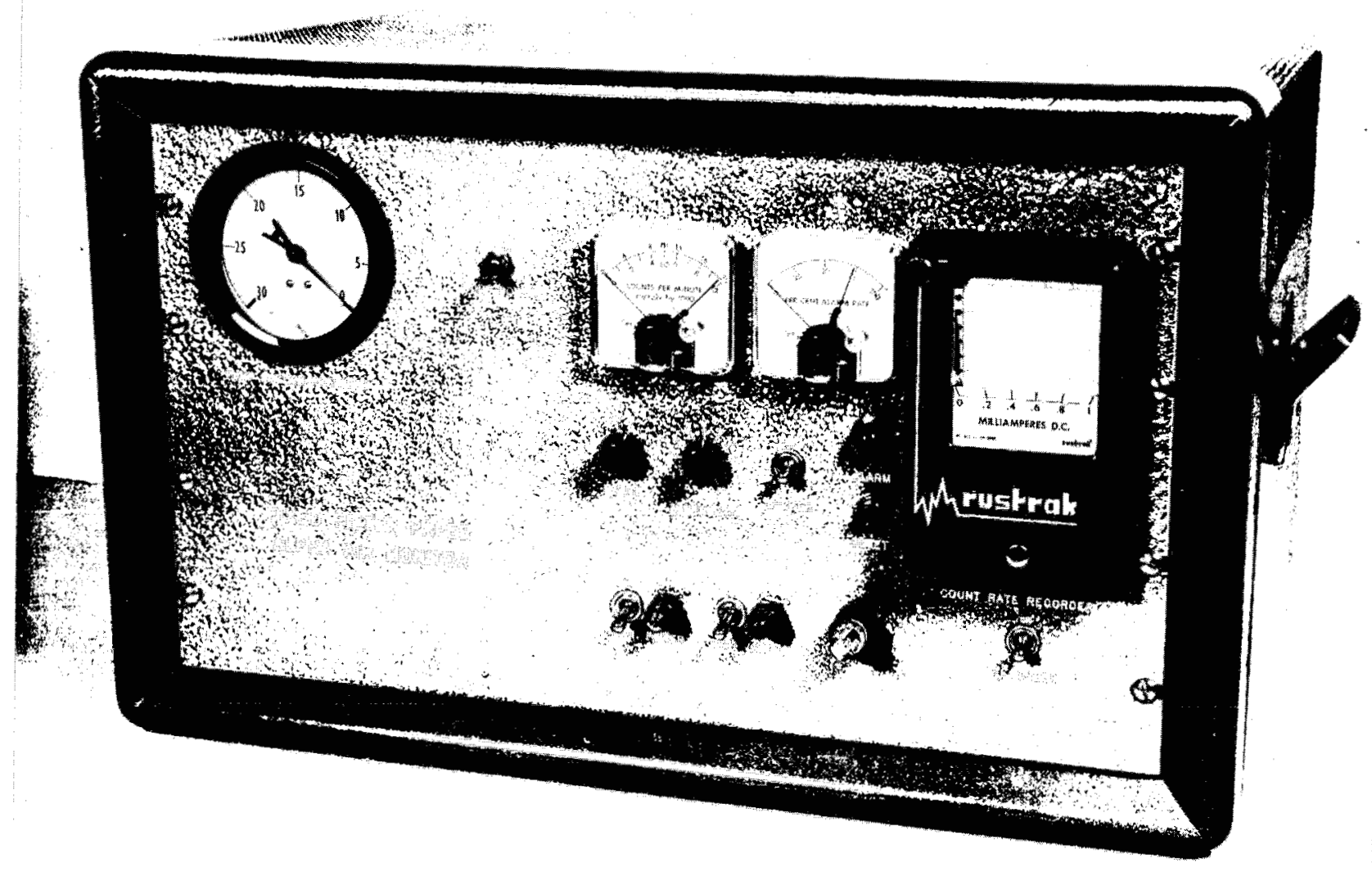

남

Figure 3

ALPHA AIR MONITOR - FRONT VIEW 


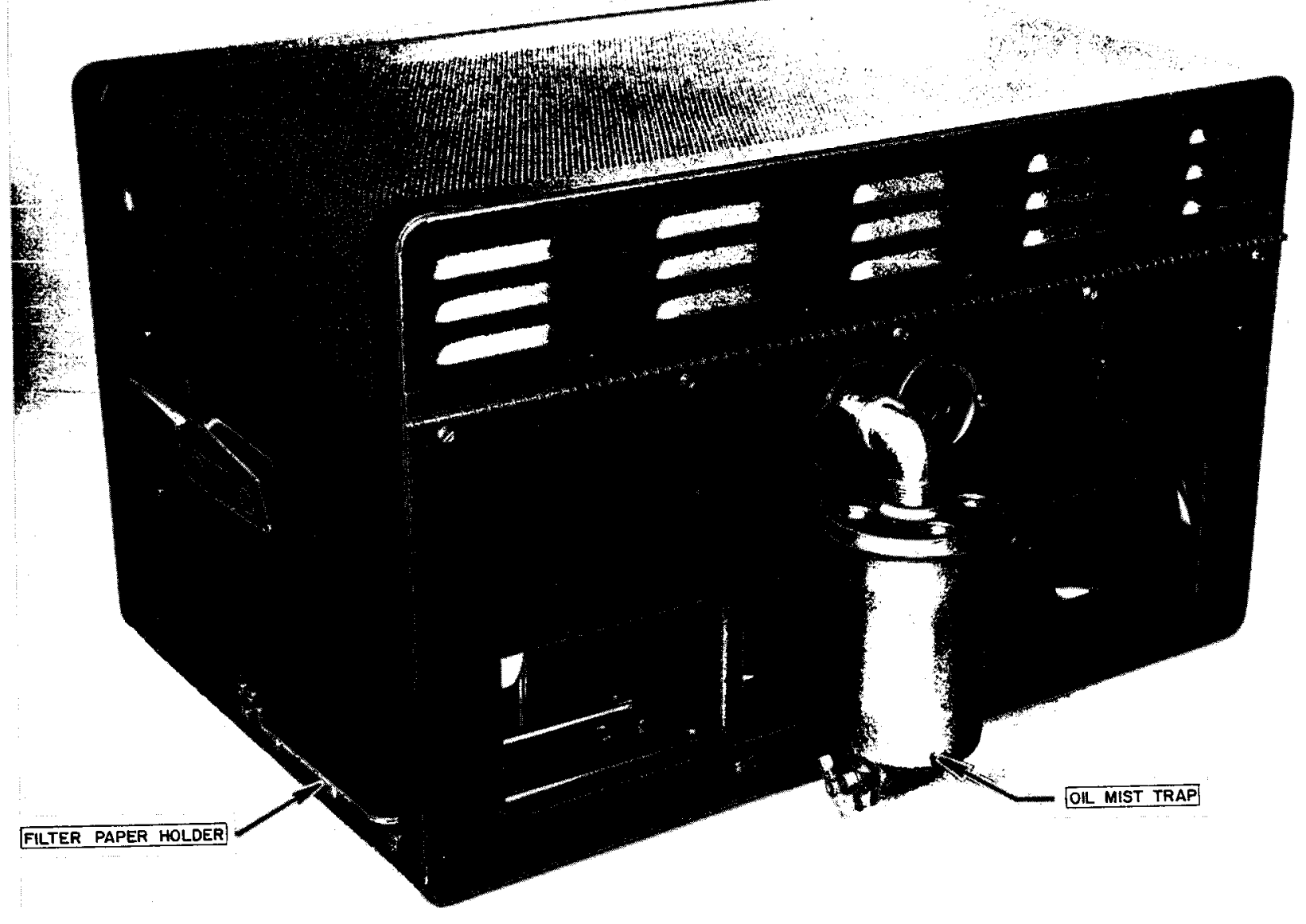

Figure 4

AIR MONITOR - REAR VIEW 


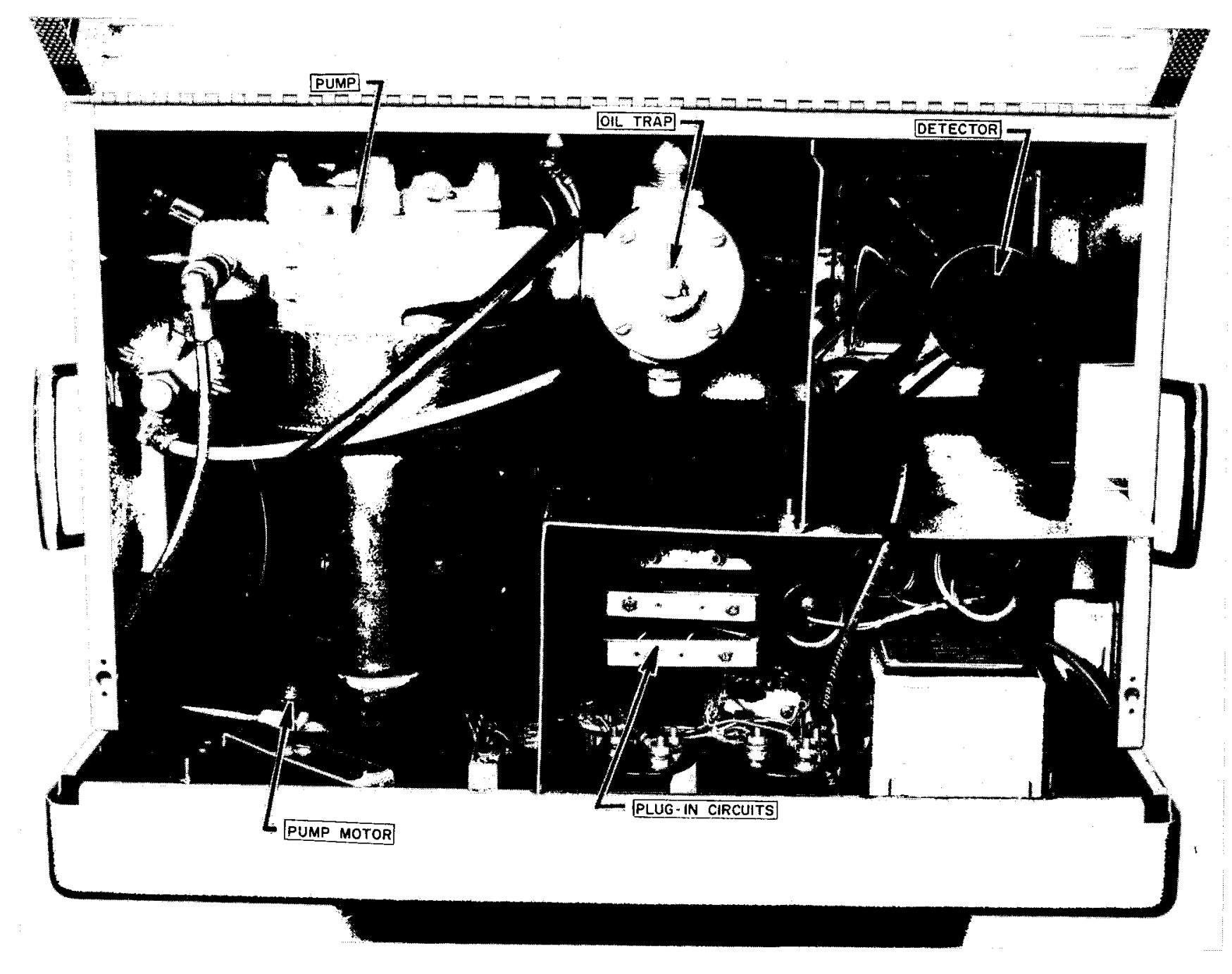

Figure 5

AIR MONITOR - TOP VIEW WITH COVER OPEN 


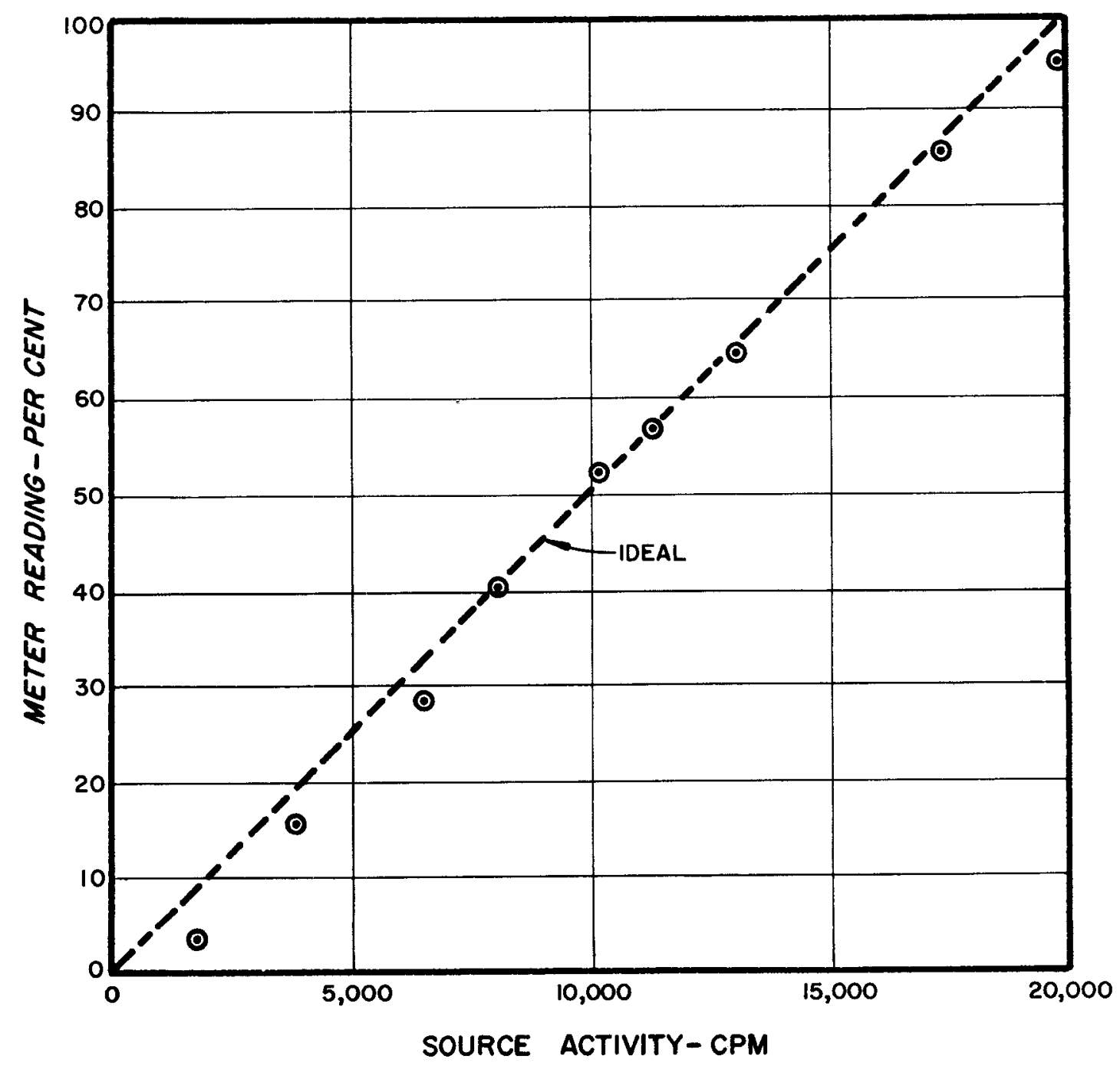

Figure 6

TYPICAL CALIBRATION 


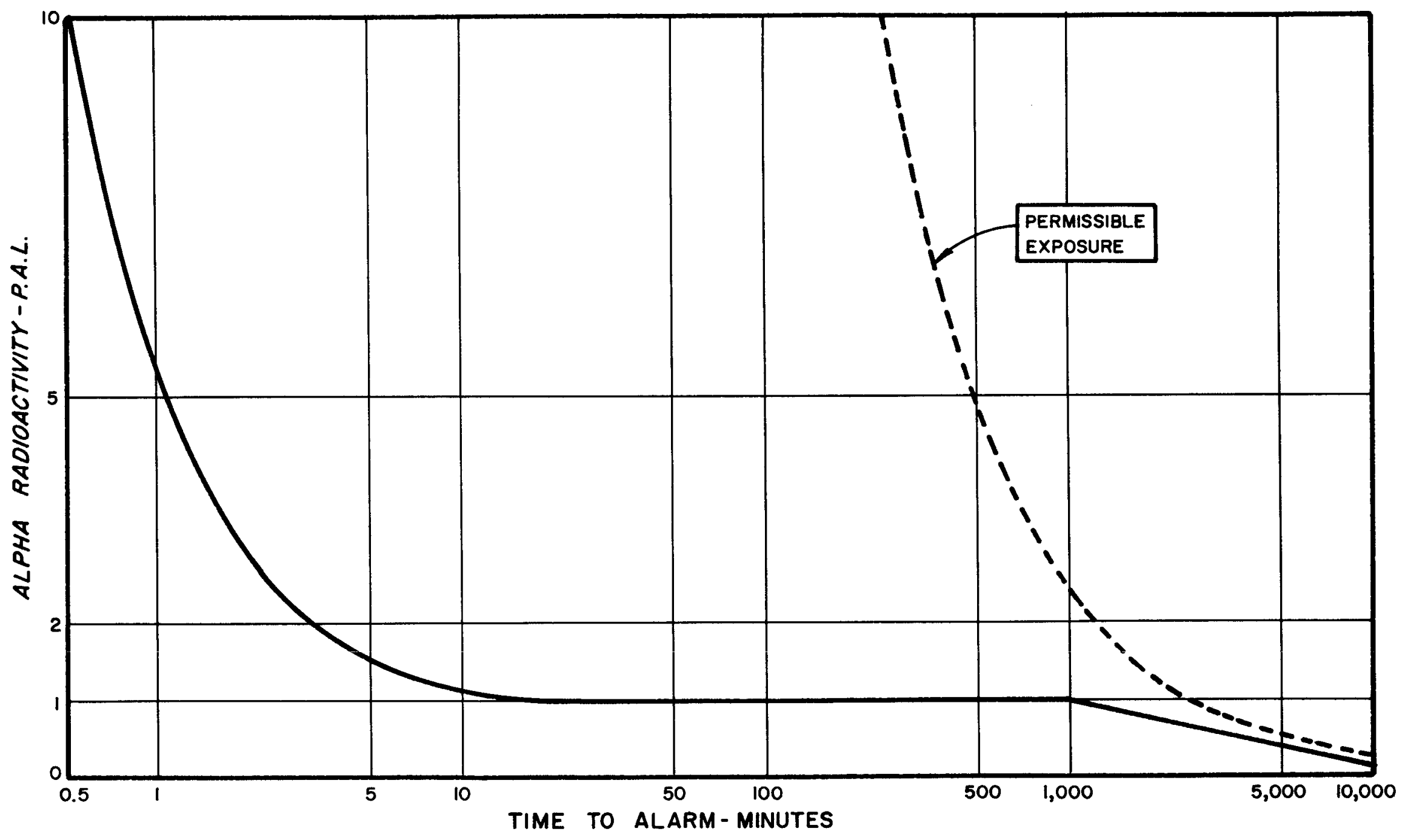

它

Figure 7

ALARM CHARACTERISTICS 

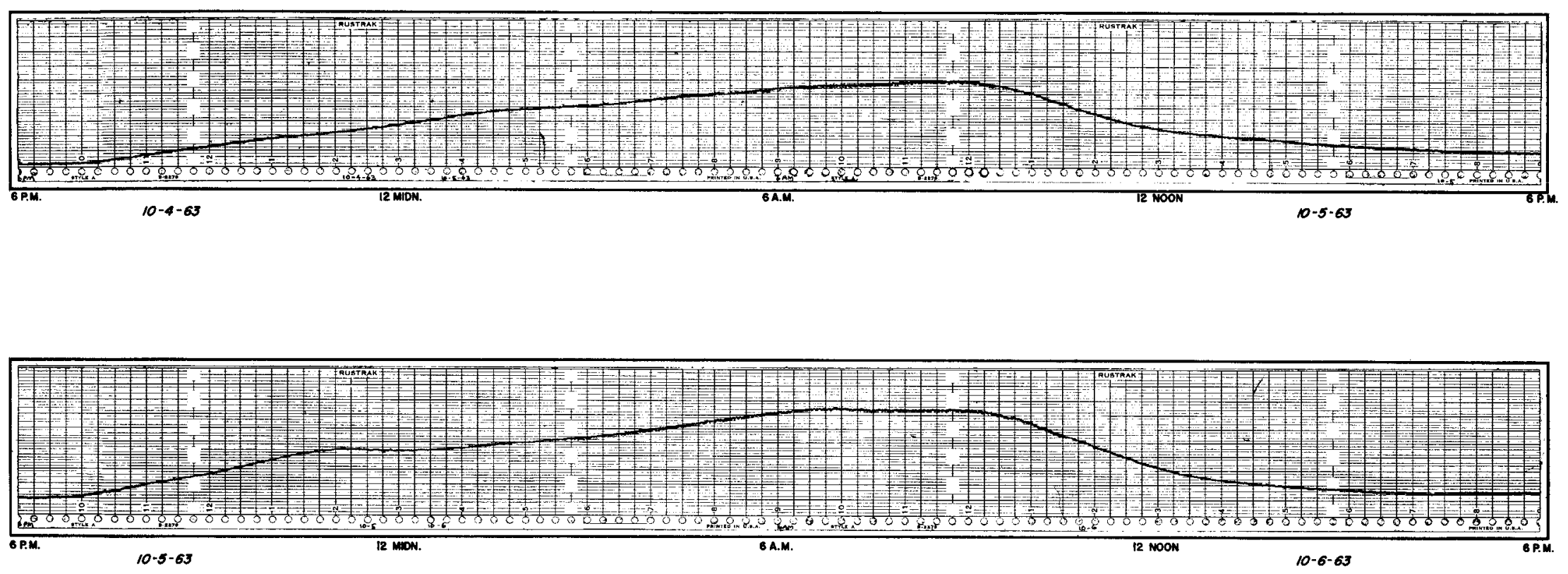

FULL SCALE IS 20,000 CPM

Figure 8

RECORDINGS OF ALPHA BACKGROUND FOR TWO CONSECUTIVE DAYS 


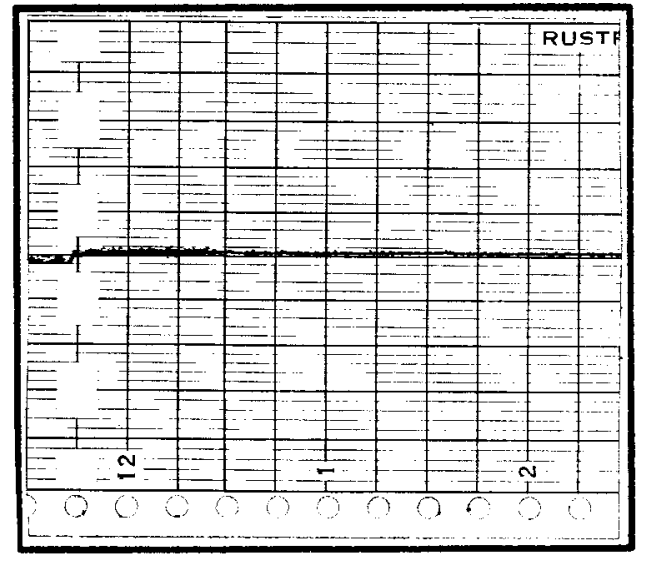

(a)

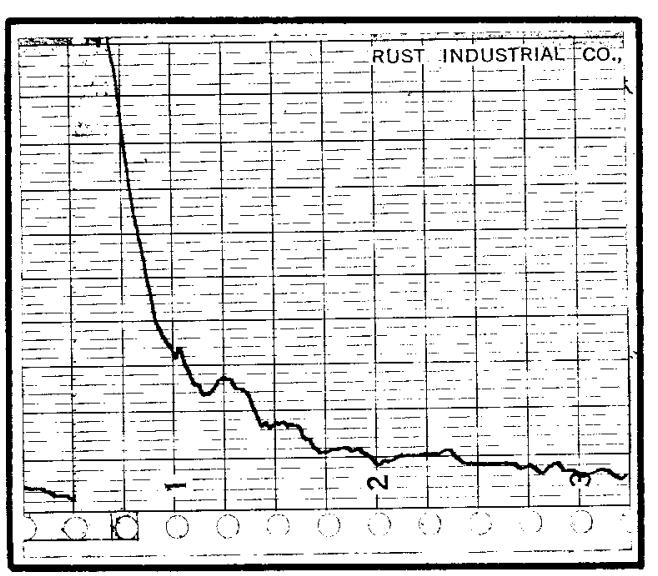

(b)

INPUT FROM PULSE GENERATOR

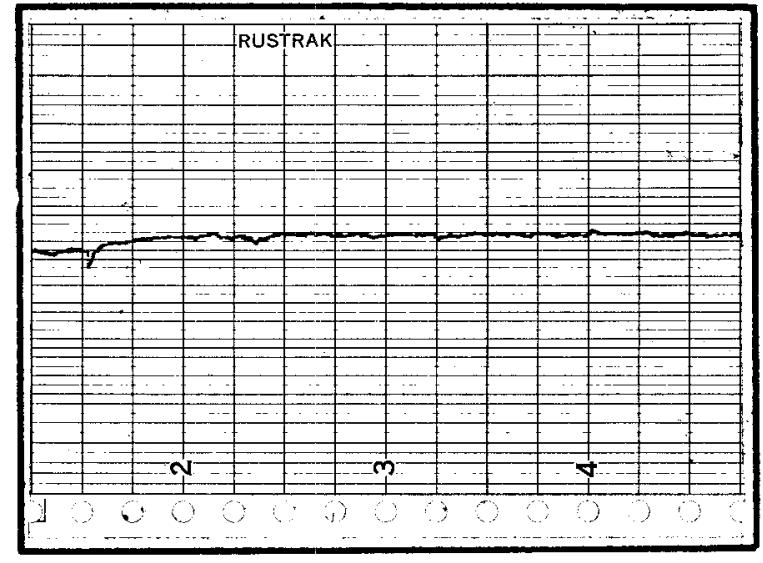

(c)

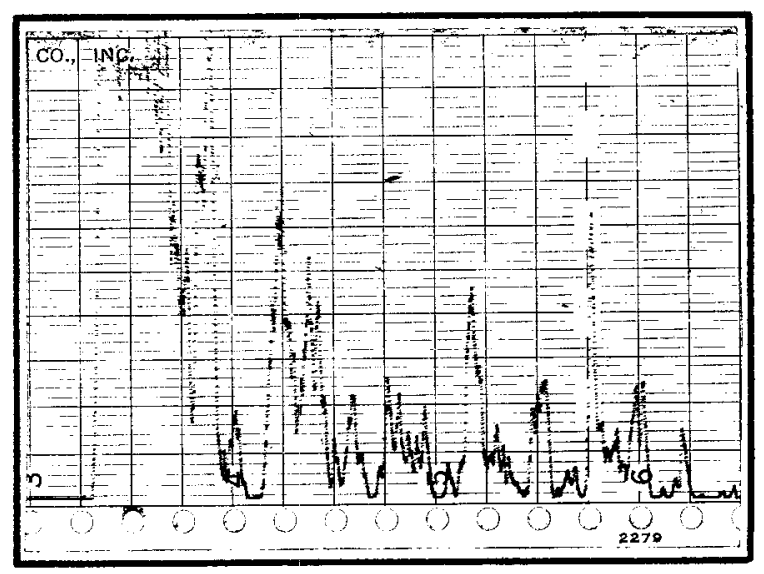

(d)

INPUT FROM DISC ALPHA SOURCES

FULL SCALE INPUT IS 20,000 CPM.

CHART SPEED IS ONE INCH PER HOUR.

Figure 9

RESPONSE OF COUNT RATE (ABOVE) AND ALARM RATE (BELOW) CIRCUITS TO STEP INCREASES IN SIGNAL INPUT 